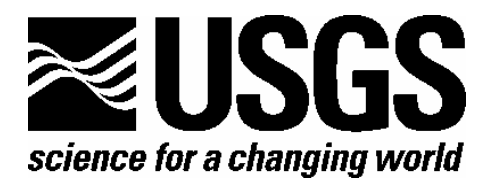

\title{
Applying the Land Use Portfolio Model to Estimate Natural-Hazard Loss and Risk-A Hypothetical Demonstration for Ventura County, California
}

\author{
By Laura B. Dinitz
}

Open-File Report 2008-1309 


\section{U.S. Department of the Interior \\ DIRK KEMPTHORNE, Secretary}

\section{U.S. Geological Survey \\ Mark D. Myers, Director}

U.S. Geological Survey, Reston, Virginia 2008

For product and ordering information:

World Wide Web: http://www.usgs.gov/pubprod

Telephone: 1-888-ASK-USGS

For more information on the USGS-the Federal source for science about the Earth,

its natural and living resources, natural hazards, and the environment:

World Wide Web: http://www.usgs.gov

Telephone: 1-888-ASK-USGS

Suggested citation:

Dinitz, L.B., 2008, Applying the Land Use Portfolio Model to estimate natural-hazard loss and risk; a hypothetical demonstration for Ventura County, California: U.S. Geological Survey Open File Report 2008-1309, 12 p.

[http://pubs.usgs.gov/of/2008/1309/].

Any use of trade, product, or firm names is for descriptive purposes only and does not imply endorsement by the U.S. Government.

Although this report is in the public domain, permission must be secured from the individual copyright owners to reproduce any copyrighted material contained within this report. 


\section{Contents}

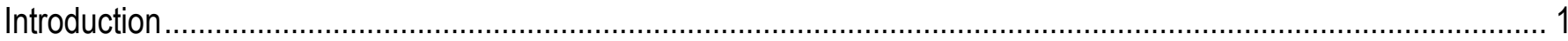

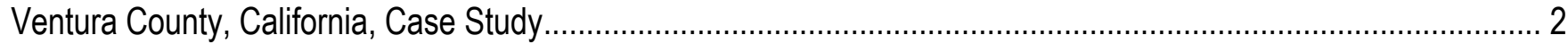

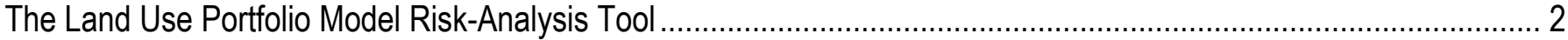

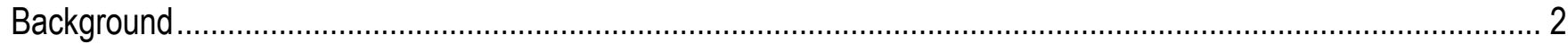

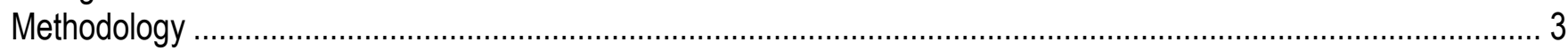

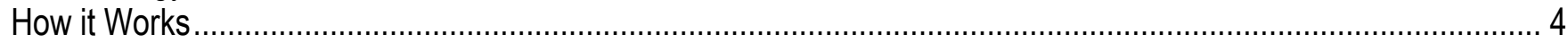

Hypothetical Portfolio Analysis for Ventura County ……………................................................................

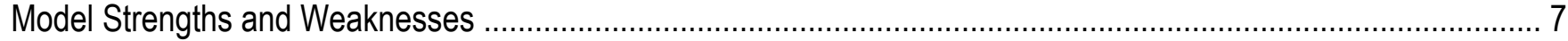

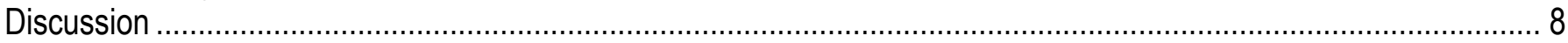

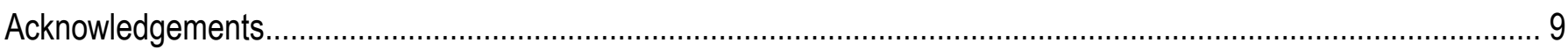

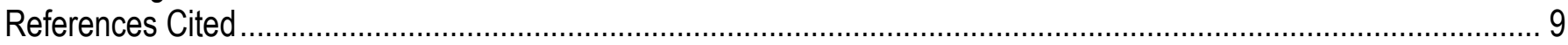

\section{Figures}

1. Map of Ventura County showing the extent of the California Geological Survey study region.

2. The Land Use Portfolio Model and Ventura County showing residential parcels selected for a hypothetical mitigation action, California Geological Survey (CGS) preliminary landslide inventory, CGS landslide hazard susceptibility zones, and parcels in the CGS study region.

\section{Tables}

1. Land Use Portfolio Model results (dollar values in \$million) for hypothetical Scenarios 1 and 2, for Ventura County, California, with mitigation effectiveness of 100 percent and 80 percent, respectively. 


\title{
Applying the Land Use Portfolio Model to Estimate Natural-Hazard Loss and Risk-A Hypothetical Demonstration for Ventura County, California
}

\author{
By Laura B. Dinitz
}

\section{Introduction}

With costs of natural disasters skyrocketing and populations increasingly settling in areas vulnerable to natural hazards, society is challenged to better allocate its limited risk-reduction resources. In 2000, Congress passed the Disaster Mitigation Act, amending the Robert T. Stafford Disaster Relief and Emergency Assistance Act (Robert T. Stafford Disaster Relief and Emergency Assistance Act, Pub. L. 93-288, 1988; Federal Emergency Management Agency, 2002, 2008b; Disaster Mitigation Act, 2000), mandating that State, local, and tribal communities prepare natural-hazard mitigation plans to qualify for pre-disaster mitigation grants and post-disaster aid. The Federal Emergency Management Agency (FEMA) was assigned to coordinate and implement hazard-mitigation programs, and it published information about specific mitigation-plan requirements and the mechanisms (through the Hazard Mitigation Grant Program-HMGP) for distributing funds (Federal Emergency Management Agency, 2002). FEMA requires that each community develop a mitigation strategy outlining long-term goals to reduce natural-hazard vulnerability, mitigation objectives and specific actions to reduce the impacts of natural hazards, and an implementation plan for those actions. The implementation plan should explain methods for prioritizing, implementing, and administering the actions, along with a "cost-benefit review" justifying the prioritization.

FEMA, along with the National Institute of Building Sciences (NIBS), supported the development of HAZUS ("Hazards U.S."), a geospatial natural-hazards loss-estimation tool, to help communities quantify potential losses and to aid in the selection and prioritization of mitigation actions. HAZUS was expanded to a multiple-hazard version, HAZUS-MH, that combines population, building, and natural-hazard science and economic data and models to estimate physical damages, replacement costs, and business interruption for specific natural-hazard scenarios. HAZUS-MH currently performs analyses for earthquakes, floods, and hurricane wind.

HAZUS-MH loss estimates, however, do not account for some uncertainties associated with the specific natural-hazard scenarios, such as the likelihood of occurrence within a particular time horizon or the effectiveness of alternative risk-reduction options. Because of the uncertainties involved, it is challenging to make informative decisions about how to cost-effectively reduce risk from natural-hazard events. Risk analysis is one approach that decision-makers can use to evaluate alternative risk-reduction choices when outcomes are unknown. The Land Use Portfolio Model (LUPM), developed by the U.S. Geological Survey (USGS), is a geospatial scenario-based tool that incorporates hazard-event uncertainties to support risk analysis. The LUPM offers an approach to estimate and compare risks and 
returns from investments in risk-reduction measures. This paper describes and demonstrates a hypothetical application of the LUPM for Ventura County, California, and examines the challenges involved in developing decision tools that provide quantitative methods to estimate losses and analyze risk from natural hazards.

\section{Ventura County, California, Case Study}

Ventura County (VC), California, was selected as the study area for the hypothetical demonstration analysis for three reasons. First, the community is vulnerable to many natural hazards, including fault rupture, ground shaking, liquefaction, tsunami, seiche (similar to a tsunami, but occurring in a closed or restricted body of water such as a lake), landslides/mudslides, subsidence, expansive soils, floods, dam-failure inundation, coastal wave and beach erosion, and wildfires (County of Ventura, 2005a, 2005b). Second, State and local governments have produced many geospatial natural-hazard datasets needed for the analyses, many of which are accessible online. Finally, the California State Office of Emergency Services and other agencies expressed interest in the USGS applying the LUPM in VC.

VC is in southern California along the Pacific Ocean between Santa Barbara and Los Angeles Counties (fig. 1). According to the U.S. Census Bureau's 2000 census, the population of VC was 753,197 , and by 2006 it was estimated to be nearly 800,000 (U.S. Census Bureau, 2008). The total area of the county is 2,208 square miles, 1,845 square miles of which is land area, and the is rest water. The total area includes Anacapa Island of the Channel Islands and San Nicolas Island. Most of the population in VC lives in the southern part of the county; the northern part is rugged and mountainous. VC has a broad economic base with a large and diverse labor pool and major industries including agriculture, biotechnology, telecommunications and advanced technologies, manufacturing, tourism, and military testing and development (County of Ventura, 2002). Agriculture is particularly important; $\mathrm{VC}$ is among the top agricultural production counties in California, and it has an annual crop value of more than $\$ 1$ billion.

\section{The Land Use Portfolio Model Risk-Analysis Tool}

\section{Background}

The LUPM is a geospatial scenario-based risk-analysis tool, which estimates return-oninvestment and uncertainty for portfolios of natural-hazard risk-reduction measures and mitigated locations. The model is inspired by financial-portfolio theory, a method for evaluating alternative, regional-scale investment possibilities on the basis of their estimated distributions of risk and return (Sharpe, 1970). The model is general enough to be applied to any hazard, though it may be difficult to acquire accurate estimates for some of the information required to run the model. The LUPM integrates natural-hazards, earth-science, and economic information in a Geographic Information System (GIS) to estimate expected value and uncertainty of return-on-investment, expected loss, and expected value and uncertainty of community wealth retained. For a natural-hazard event, a user can run the LUPM to evaluate the risks and returns of investing in different portfolios of locations and loss-mitigation strategies, and then compare and rank them according to the user's risk preferences (Bernknopf and others, 2006; Dinitz and others, 2003). The LUPM was designed for decision-making at a regional- 
level, but data at any scale can be entered into the model. For example, it would be appropriate to use parcel-level data for making loss-mitigation investment decisions that involve actions taken at the parcel level. It also is easy to rerun the model with updated or alternative datasets as more current or accurate data becomes available.

Three versions of the LUPM software are under development. Two are designed to work primarily within an ArcGIS application environment, such as ArcMap. These versions include an ArcGIS tool extension and an ArcGIS Model Builder tool accessible through ArcGIS Toolbox. Both versions will be packaged together and released to USGS researchers and partners as LUPM Version 1.0. The ArcGIS tool extension features a Database Setup Manager interface to store hazard and scenario data, a Hazard Events Manager interface to maintain natural-hazard classes and events information, and a Scenarios Manager interface to manage scenarios information (fig. 2). The Model Builder tool features a set of LUPM geoprocessing tools. A tutorial is included to guide users through the essential steps. The tutorial also includes information about utilizing HAZUS-MH to obtain lossestimate and other pertinent data, formatting data, running the model, and understanding the results from several comparative scenarios. For each scenario, the LUPM generates a report summarizing the effects of a loss-mitigation portfolio on community wealth. The report, along with output for each parcel, can be saved to the database for future reference. A third version of the LUPM software under development is a Web deployment that is designed to allow users to define scenarios and run the LUPM calculations online.

\section{Methodology}

The core of the LUPM consists of a set of equations derived from portfolio theory (Bernknopf and others, 2001, 2006; Champion, 2008). The focus of the LUPM is on quantifying the impacts of alternative natural-hazard risk-reduction choices by communities facing risks from one or many natural hazards. For each project or application of the LUPM, decision makers must carefully scope the problem to define several aspects, beginning with which hazard to analyze. For communities facing multiple hazards, it is not always readily apparent which hazard is of greatest concern. Decision makers need to define objectives and identify natural-hazard scenarios, the geographic extent of the study area, damage parameters for the hazard event, community values at risk, viable loss-reduction measures and their costs, and the planning-time horizon. Natural-hazard scenarios are defined by the type, severity, and likelihood of the hazard event. Examples of community asset values are casualties, structural (such as parcel values) and infrastructure (such as roads and bridges) replacement costs, business interruption, and critical facility downtime. The user also has the option to include estimates of the effectiveness of the risk-reduction measures. Users provide all necessary geospatial input data and can update the datasets and rerun the LUPM as newer or more accurate data becomes available. The LUPM is flexible enough to analyze any type of hazard, so long as the data needed by the model is available.

There are a number of ways to estimate asset values for the LUPM. There is also an ongoing debate between engineering and economics researchers about whether to use replacement or market values for properties. Replacement values primarily consider the actual cost of rebuilding a damaged structure, while market values also consider attributes that impact the price that potential buyers are willing to pay for a parcel. Examples of these attributes include the reputation of local neighborhood schools, or a spectacular view. The availability of asset values varies by asset type. Estimates of residential parcel values can be found in real-estate databases provided by companies such as DQNews (2008). For example, DQNews publishes online median home prices per square foot for single-family residential properties by zip code that can be used to estimate market values. Another approach is to 
estimate market values through hedonic price modeling, which uses information about actual past sales and the attributes of parcels sold to estimate market values for other parcels with similar attributes (Rosen, 1974). A third approach is to use appraisal values from the county tax assessor's office. It can be particularly difficult to estimate values for other types of structures and infrastructure. For example, for infrastructure such as roads and bridges, it might make sense to use estimated replacement costs. For agricultural parcels, which are numerous in $\mathrm{VC}$, one might estimate values considering the agricultural output that would be lost if the parcel were damaged. An accurate assessment of the values at risk is important to justify the dollar investment in preventing natural-hazard losses.

The data that are probably the most difficult to acquire for the LUPM are the conditional spatialdamage probabilities. These are the probabilities that damage occurs at particular locations based on their geological and other physical attributes given that a particular natural-hazard event scenario occurs. These probabilities are estimates founded on earth-science and natural-hazard information, including data collected from past events. Because these low-probability, high-impact events rarely occur, scientists have little data and information about them and must often rely on expert opinion to fill in data gaps.

The cost of risk-reduction measures varies widely depending on the type. They can be implemented regionally, such as by restricting development near earthquake faults and in liquefaction zones, or by building berms or dikes for large-scale flood protection. Alternatively, they can be local measures, such as earthquake-retrofitting a residential structure by bolting it to its foundation, or floodretrofitting a structure by raising its elevation. Complicating matters is the fact that mitigation actions designed to reduce damage from one hazard may increase the likelihood of damage caused by another hazard. For example, raising a building to avoid floods may increase its vulnerability to shaking from earthquakes.

Model output for a specified scenario and selected portfolio consists of the total number of locations (such as parcels) within the study region, the number of mitigated locations, the original community wealth (sum of total assets plus mitigation investment), and the mitigated community wealth. Additionally, the LUPM calculates the expected values and uncertainties of losses with and without mitigation, avoided losses, retained community wealth, return-on-investment, and rate of return. The expected value of losses with mitigation is broken down into losses for mitigated and unmitigated locations. The LUPM also tabulates the number of locations selected that contribute ancillary benefits.

\section{How it Works}

The most efficient way to get started using the LUPM is to first assemble the geospatial data into a GIS. It is helpful, though not required, to collocate all data into a single layer. Once the data is prepared, the user selects a portfolio of locations to be mitigated and/or risk-reduction measures to be applied. An excellent approach for this step is to use the selection tools available in the GIS. A user might select a set of locations by their attributes according to a specific strategy or policy, such as lowincome residential parcels, all schools within a county, or parcels within high-susceptibility zones.

Next, the user is ready to launch the LUPM software. This description uses the LUPM ArcGIS tool extension. Within the LUPM module, the user opens the Database Setup Manager to create a database (or open a previously created one) for storing the hazard and scenario data. The next step is to open the Hazard Events Manager where the user defines the class of natural hazard (such as earthquake or flood), the specific natural-hazard event to be analyzed (such as a magnitude 6.8 earthquake or a 100year flood event), and the probability of the event. Then, for the specified hazard event, the user sets up 
the specific scenario with the Scenario Manager. For a specific scenario, the user provides a scenario name, description, and location of the primary GIS data layer, along with its unique identifying field for connecting to other data layers if necessary. Then the user identifies the layers and fields for the asset values, conditional-damage probabilities, and mitigation costs. The user can also identify the layers and fields for mitigation effectiveness data. To capture potential ancillary benefits of non-market-valued assets, users have the option to identify layers and fields of locations with special types of significance, such as safety/critical, cultural, environmental, and economic. Examples include Superfund, hospital, and historic-preservation sites.

When all layers and fields have been identified to the LUPM, the user runs the scenario. The LUPM performs the calculations and generates a report summarizing the scenario parameters and model results. The report, along with output for individual locations, can be saved to the database for future reference. Sensitivity analysis can be performed by altering one parameter at a time and analyzing the variability in the results. If small changes in parameters do not result in large changes in the output, then the model results may be considered robust.

\section{Hypothetical Portfolio Analysis for Ventura County}

The methods used to acquire the necessary information, including the data collected and assumptions made, and perform the LUPM hypothetical analysis for VC, are presented here. The analysis is hypothetical because one cannot make assumptions about the preferences or decisions that local community leaders would make, such as which hazard to address, or which investment strategies to pursue. Additionally, some data used in this analysis is incomplete or preliminary and should not be used as-is for a real analysis on which to base actual decisions. The steps for the hypothetical analysis include deciding on the hazard scenario, estimating conditional-damage probabilities, defining the strategy for selecting parcels to mitigate, identifying asset values, and estimating mitigation costs and effectiveness. We did not enter information for the optional ancillary benefits.

In defining the hazard scenario, we selected a large earthquake event occurring in the VC region. A catastrophic earthquake on the south-central San Andreas fault is likely before the end of the twentyfirst century and is estimated to have a current annual probability of occurrence between 2 and 5 percent (County of Ventura, 2005b). We assumed a worst-case-scenario earthquake hazard-event probability of 0.05 .

Damage impacts from large earthquakes can come from ground shaking, liquefaction, and landslides, among others. This VC analysis focuses on landslide hazards for reasons of data availability. As part of the California Geological Survey (CGS) Seismic Hazards Zonation Program, the CGS mapped areas of $\mathrm{VC}$ as being located either in or out of a landslide susceptibility zone (California Geological Survey, 2007b). Figure 1 shows the CGS study area for VC. These maps were created primarily for planning purposes, such as zoning and building permitting. The CGS also is in the process of publishing landslide-inventory maps that show the locations of past landslides (California Geological Survey, 2007a). At this time, the CGS landslide-inventory map for VC is still in a preliminary draft state and is being used in this analysis for demonstration purposes only. Figure 2 shows the landslidesusceptibility and landslide-inventory datasets, and we use these to calculate the conditional spatial likelihood of an earthquake-triggered landslide from the proportion of area historically impacted by landslides in each susceptibility class. The likelihood that a location "IN" the landslide hazard zone will experience an earthquake-triggered landslide failure is areaLS IN / areaIN, where areaLS IN is defined as the area measurement of landslide events "IN" the hazard zone, and areaIN is defined as the total 
area of the "IN" hazard zone within the VC study region. The likelihood that a location outside the landslide hazard zone will experience a landslide failure is areaLS OUT / areaOUT, where areaLS OUT is defined as the area measurement of landslide events "OUT" of the hazard zone, and areaOUT is defined as the total area of the study region that is not in the landslide hazard zone. The likelihoods for locations "IN" and "OUT" of the landslide-susceptibility zones were calculated as 0.20814 and 0.00643 , respectively. Landslide events that fall within the hazard zone represent actual failures in expected locations, while those that occur outside of the hazard zone represent actual failures in unexpected locations. Because the CGS does not have information on the cause or timing of the landslide, this analysis must assume that the landslides mapped in the landslide inventory were triggered by earthquakes and could occur again at the same location. In reality, however, it is likely that there were other causes, such as heavy rainfall, and the oldest landslides at a site may no longer pose a threat.

Once the conditional spatial-hazard probabilities are calculated, they must be connected to the decision unit. The decision unit for this project is the parcel. Because some parcels intersect more than one susceptibility zone, assigning the probability to parcels must be done strategically. Two example methods for assigning probabilities to parcels are (1) using the highest susceptibility zone that intersects any part of the parcel (the worst-case scenario), and (2) using the susceptibility zone that intersects the greatest area of the parcel. This analysis uses the second method.

The mitigation-investment strategy for selecting parcels in this analysis is to select those designated as residential land-use type and located within the CGS hazard-susceptibility zone. For simplification, only low-rise residential parcels in which the lot square footage is larger than the total floor square footage are included. In our dataset, this selection consists of 957 residential parcels (fig. 2). The VC Assessor's Office offers maps of parcel boundaries (Ventura County Assessor's Office, 2006) and provided a complete listing of use codes and the associated uses. We generalized the use codes into major land-use categories, including single-family residential, multifamily residential, agriculture, commercial/industrial, infrastructure, medical facility, open improved, public/government, school, undeveloped, vacant, and other. We computed residential parcel values by using publicly available data, including sale price per zip code and structure square footage provided online by DQNews.

Examples of landslide hazards-mitigation strategies for existing development include slope stabilization, restraining walls, piles, and surface- and ground-water drainage controls (Spiker and Gori, 2000). For simplification, this analysis estimates costs for earthquake-triggered landslide mitigation actions as a percentage of parcel value. Specifically, the analysis assumes a cost of 10 percent of the parcel value. Finally, although implementing such risk-reduction measures often reduces the likelihood and severity of damage from an earthquake, it does not guarantee that a parcel will be fully protected (California Seismic Safety Commission, 2005). This analysis consists of model runs for two scenarios. Scenario 1 assumes that the mitigation measures protect a parcel completely, while Scenario 2 assumes the mitigation measures to be 80 percent effective. The model results are shown in table 1 . Reducing the mitigation-effectiveness parameter in Scenario 2 results in increased expected values and uncertainties of losses from mitigated parcels and decreased return on investment, as compared to Scenario 1. 
Table 1. Land Use Portfolio Model results (dollar values in \$million) for hypothetical Scenarios 1 and 2, for Ventura County, California, with mitigation effectiveness of 100 percent and 80 percent, respectively.

\begin{tabular}{lll}
\hline Model output variables & Scenario 1 & Scenario 2 \\
\hline Number of parcels & & \\
Number of mitigated parcels & 213,527 & 213,527 \\
Original wealth & 957 & 957 \\
Total assets & $\$ 180,325,741.3$ & $\$ 180,325,741.3$ \\
Mitigation investment & $\$ 180,325,668.5$ & $\$ 180,325,668.5$ \\
Mitigated wealth & $\$ 72.8$ & $\$ 72.8$ \\
Expected losses with no mitigation & $\$ 101,778.4+/-\$ 447,772.8$ & $\$ 128.2$ \\
Expected losses with mitigation & $\$ 101,770.8+/-\$ 447,740.1$ & $\$ 101,776.9+/-\$ 447,766.3$ \\
From mitigated parcels & $\$ 0.0$ & $\$ 6.1$ \\
From unmitigated parcels & $\$ 101,770.8$ & $\$ 101,770.8$ \\
Expected avoided losses & $\$ 7.6+/-\$ 33.1$ & $\$ 1.5+/-\$ 6.6$ \\
Expected retained wealth & $\$ 180,223,897.6+/-\$ 447,740.1$ & $\$ 180,223,891.6+/-\$ 447,766.3$ \\
Expected return & $\$ 7.6+/-\$ 33.1$ & $\$ 1.5+/-\$ 6.6$ \\
Expected rate of return & $10.4 \%+/-45.5 \%$ & $2.1 \%+/-9.1 \%$ \\
Ancillary benefits & None & None \\
Number of parcels & 213,527 & 213,527 \\
\hline
\end{tabular}

\section{Model Strengths and Weaknesses}

The LUPM has many strengths as a risk-analysis tool. Most importantly, the LUPM provides a quantitative method to examine the potential benefits of implementing alternative risk-reduction measures for multiple hazard scenarios while taking into account the uncertainties, or risk, associated with hazards and mitigation effectiveness. For example, one might compare community-wide versus site-by-site measures. It also can play a role in helping communities identify which hazards to select for evaluation by examining a distribution of potential damages. The LUPM is designed to be flexible; it can be applied to any hazard of interest to a community and at any scale for which data is available. A user can do sensitivity analysis to evaluate how input parameters impact model output, and the software can perform batch runs with ranges of parameters to rapidly generate numerous model results for analysis and comparison.

We continue to enhance the LUPM methodology. We would like to improve the current measurement of uncertainty to better suit the model and the needs of decision makers. We also want to develop a more streamlined approach for the LUPM to perform risk analysis (rather than users doing the risk analysis with the LUPM results) by updating it to calculate and analyze model results for multiple hazard scenarios (rather than for a single hazard scenario with multiple parameters). The model is still in the research stage, and the software is not ready for general distribution and use; it is designed in a general way and must be tailored carefully to each particular application. Finally, to run the software, 
one must provide all necessary information, and acquiring data for low-probability, high-impact events can be challenging given the scarce data available from infrequent past events.

\section{Discussion}

The goal of the LUPM is to provide new information about natural-hazards that community leaders can use to assess and analyze risk to guide response and planning decisions. LUPM users can compare and then choose from multiple, alternative, local- or regional-level potential risk-reduction actions according to the model's expected loss, return-on-investment, and community-wealth estimates and uncertainties. Users can account for noneconomic community values, such as protecting special environmental or historic sites. Furthermore, users can apply the model results to make decisions according to their own definition and acceptable limit of risk, be it a maximum expected loss, a minimum return-on-investment, or some other measure.

A future research direction is to develop methods to link the LUPM with FEMA's HAZUS-MH loss-estimation tool. HAZUS-MH integrates building data, physical-science and engineering models, U.S. census data, and economic information in a GIS to estimate physical damage to structures, such as buildings and infrastructure; economic losses, such as business interruption and repair costs; and social impacts, such as displaced households and shelter requirements (Federal Emergency Management Agency, 2008a), for three types of hazard - earthquakes, floods, and hurricane winds. The software includes a prepackaged set of geospatial, regional-scale, base datasets for the entire United States. The goal is to utilize HAZUS-MH's inventory data, intermediate data (such as damage-state probabilities), and loss estimates as inputs to the LUPM's methodology for analyzing risk-reduction strategies. The integration of loss-estimation and risk-analysis tools can offer a more comprehensive approach that will create an overall better tool for decision makers.

Providing information about potential natural-hazard losses along with a quantitative way for decision makers to prioritize risk-reduction measures and justify the prioritization are objectives that match those stated by the DMA (2000). As mentioned in the Introduction, DMA of 2000 requires communities to create pre-disaster mitigation plans to qualify for pre-disaster mitigation grants and post-disaster aid. Communities must outline a mitigation strategy with long-term goals for reducing hazard vulnerability, specific mitigation actions to reduce the impacts of each hazard, an implementation plan detailing methods for prioritizing, implementing, and administering actions, and a "cost-benefit review" justifying the prioritization. The County of Ventura submitted the MultiJurisdictional Hazard Mitigation Plan for Ventura County, California (2005) to meet the DMA requirement, and FEMA approved it. The report contains a detailed exposure analysis for the county using the most up-to-date data and information. It lists a set of actions and prioritizes them into three categories (high, medium, and low) with descriptive, but not quantitative, economic justifications. Two examples are the City of Ventura's Action Item \#6 (Wild land fires are a major threat to a large number of residences), and unincorporated Ventura County's Action Item \#8 (Mitigation funding will help reduce potential repair and replacement costs caused by future landslide and liquefaction events). It is extremely challenging to perform quantitative cost-benefit analyses to justify prioritization of mitigation actions given the lack of available resources and well-defined methods, however, using a combination of tools like HAZUS-MH and the LUPM can serve to fill this need. 


\section{Acknowledgements}

The author would like to thank Sharon Metzler, Rich Bernknopf, Peter Ng, Sharyl Rabinovici, Anne Wein, Chris Hitchcock (William Lettis and Associates), and Tim McCrink (California Geological Survey) for their vital contributions to this paper. Additionally, thanks to Richard Champion and David Strong for their thoughtful reviews. This research has been supported by the USGS Geographic Analysis and Monitoring Program.

\section{References Cited}

Bernknopf, R.L., and others, 2001, A portfolio approach to evaluating natural hazard mitigation policies-An application to lateral-spread ground failure in coastal California: International Geology Review, v. 43, p. 424-440.

Bernknopf, R.L., and others, 2006, The influence of hazard models on GIS-based regional risk assessments and mitigation policies: International Journal of Risk Assessment and Management, v. 6, nos. 4-6, p. 369-387.

California Geological Survey, 2007a, Landslide inventory maps: [www.consrv.ca.gov/cgs/information/publications/Pages/LSIM_index.aspx, last accessed June 20, 2008].

California Geological Survey, 2007b, Seismic hazards zonation program: [http://www.conservation.ca.gov/cgs/shzp/Pages/Index.aspx, last accessed June 20, 2008].

California Seismic Safety Commission, 2005, The homeowner's guide to earthquake safety: SSC No. 05-01.

Champion, R.C., 2008, A Bernoulli formulation of the Land Use Portfolio Model: U.S. Geological Survey Open File Report 2008-1310.

County of Ventura, 2002, Visitor center, Ventura County, California:

[www.countyofventura.org/visitor/visitor.asp, last accessed June 6, 2008].

County of Ventura, 2005a, Ventura County General Plan-Goals, policies, and programs: California, County of Ventura, Resource Management Agency, Planning Division, amended by the Ventura County Board of Supervisors on Dec. 6, 2005.

County of Ventura, 2005b, Ventura County General Plan-Hazards appendix: California, Ventura County, Resource Management Agency, Planning Division. Amended by the Ventura County Board of Supervisors on Nov. 15, 2005.

Dinitz, L., and others, 2003, Evaluation of natural hazard mitigation alternatives using a geographic information system and financial portfolio theory: Proceedings of the Disaster Resistant California Conference, April 2003, San Jose, California, p. 1-10.

Disaster Mitigation Act of 2000, Pub. L. 106-390, October 30, 2000, 114 Stat. 1552.

DQNews, 2008, Southern California home resale activity (median home price per square foot by zip code): [http://www.dqnews.com/Charts/Monthly-Charts/LA-Times-Charts/ZIPLAT.aspx, last accessed August 27, 2008].

Federal Emergency Management Agency, 2002, Hazard Mitigation Planning and Hazard Mitigation Grant Program; Interim Final Rule, Part III, 44 CFR Parts 201 and 206: Federal Register, v. 67, no. 38/Tuesday, February 26, 2002/Rules and Regulations, p. 8844-8854.

Federal Emergency Management Agency, 2008a, HAZUS-MH home Web site:

[www.fema.gov/plan/prevent/hazus/index.shtm, last accessed June 6, 2008]. 
Federal Emergency Management Agency, 2008b, Summary of The Disaster Mitigation Act of 2000: [www.fema.gov/plan/mitplanning/dma.shtm, last accessed June 6, 2008].

Robert T. Stafford Disaster Relief and Emergency Assistance Act, Pub. L. 93-288, (November 23, 1988), Ch. 68 Disaster Relief, 42 U.S.C. 5121 et seq.

[www.access.gpo.gov/uscode/title42/chapter68_html, last accessed June 6, 2008].

Rosen, S., 1974, Hedonic prices and implicit markets: Journal of Political Economy, v. 82, 1974, p. 3455.

Sharpe, W.F., 1999, Portfolio theory and capital markets: New York, McGraw-Hill, 316 p.

Spiker, E.C., and Gori, P.L., 2000, National landslide hazards mitigation strategy-A framework for loss reduction: U.S. Geological Survey Open File Report 00-450.

URS Corporation (prepared for the County of Ventura), 2005, Multi-jurisdictional hazard mitigation plan for Ventura County, California.

U.S. Census Bureau, 2008, State and county quickfacts for Ventura County, California: [quickfacts.census.gov/qfd/states/06/06111.html, last accessed June 6, 2008].

Ventura County Assessor's Office, 2006, GIS parcel data and technical information: [gis.countyofventura.org/getparcels.html, last accessed June 6, 2008]. 


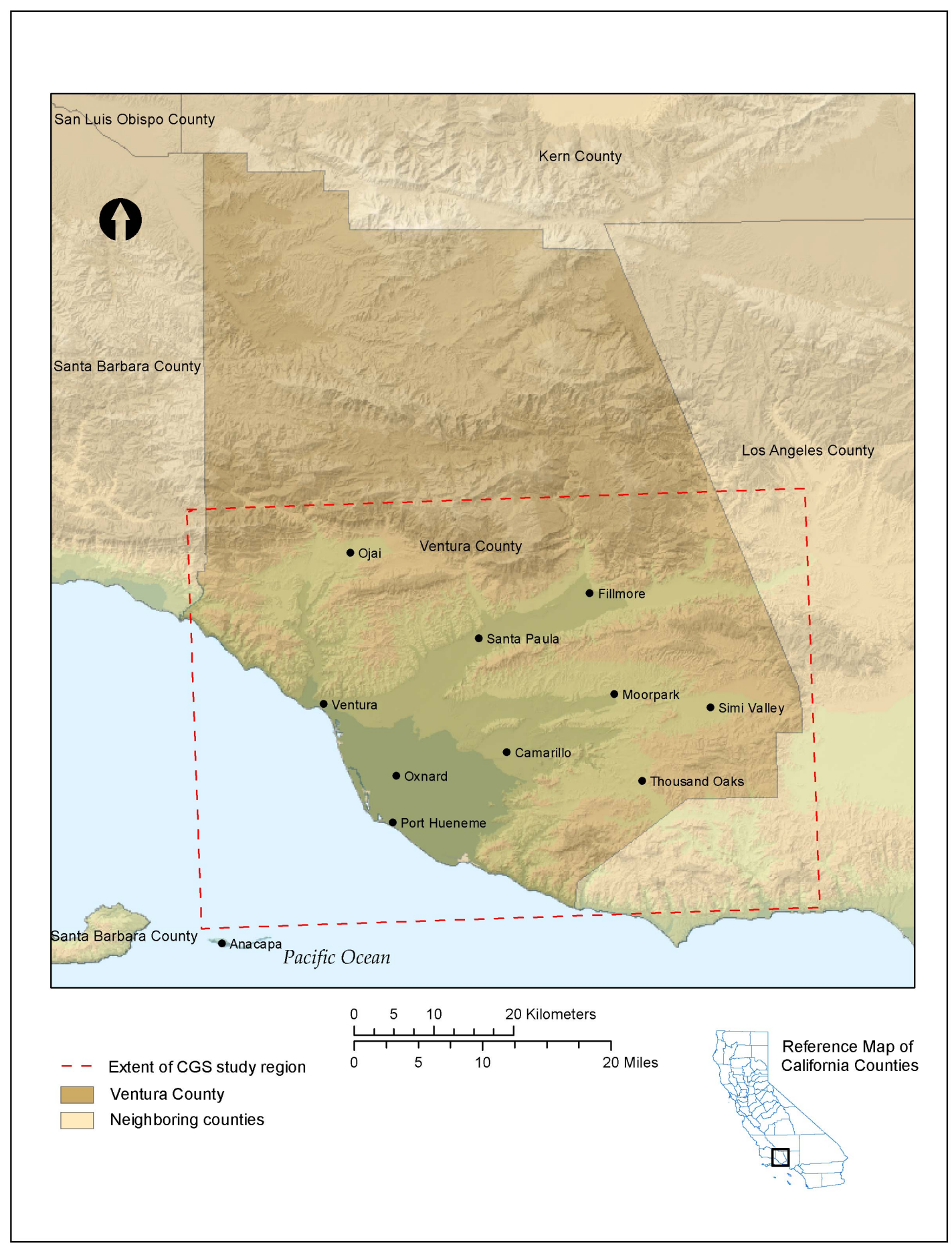

Figure 1. Map of Ventura County showing the extent of the California Geological Survey study region. 


\section{Add/Edit Scenario}

General |Communty Assets | Ancillary Benefits |

Scenario

EQtriggered LS. Scenario2

Description *

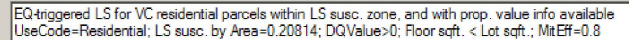

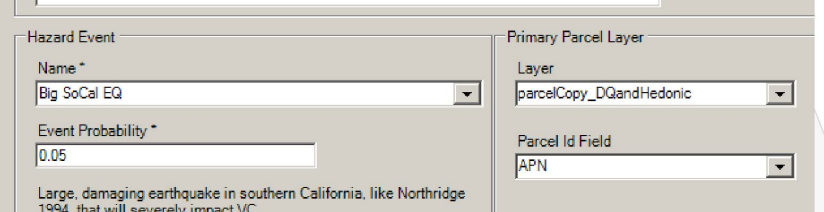

Large, damaging earthquake in southern California, like Northridge
1994. that will severely impact VC. 994. that will severely impact VC.

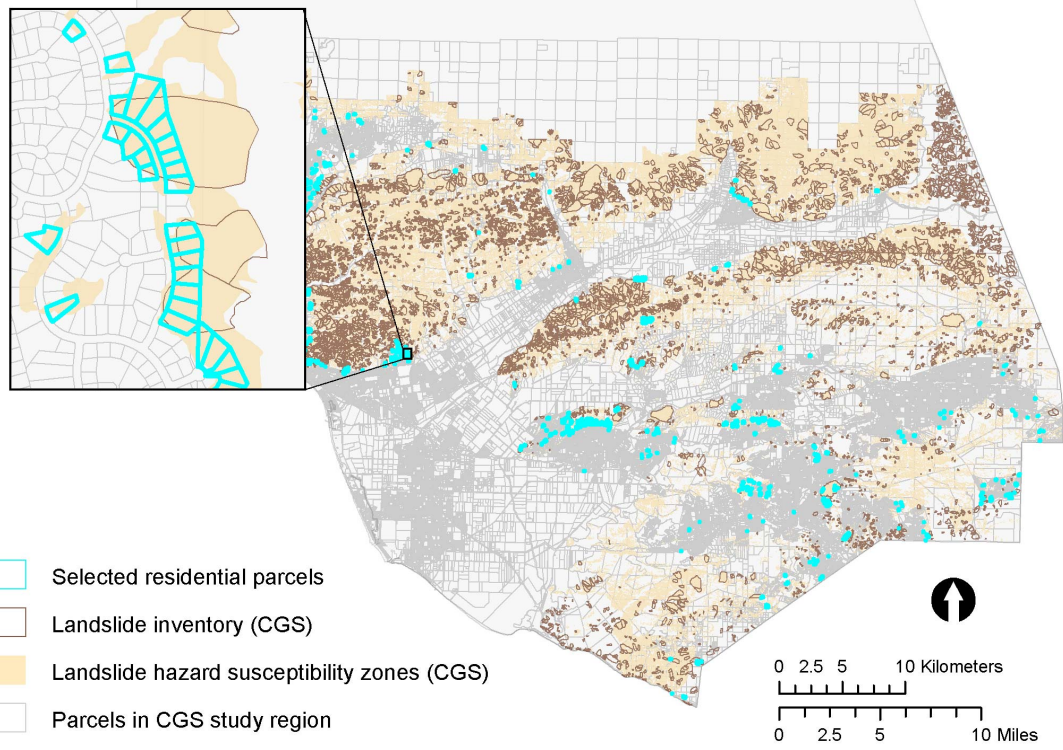

Figure 2. The Land Use Portfolio Model and Ventura County, showing residential parcels selected for a hypothetical mitigation action, California Geological Survey (CGS) preliminary landslide inventory, CGS landslide-hazard susceptibility zones, and parcels in the CGS study region. 